\title{
Faça sua realidade você mesmo
}

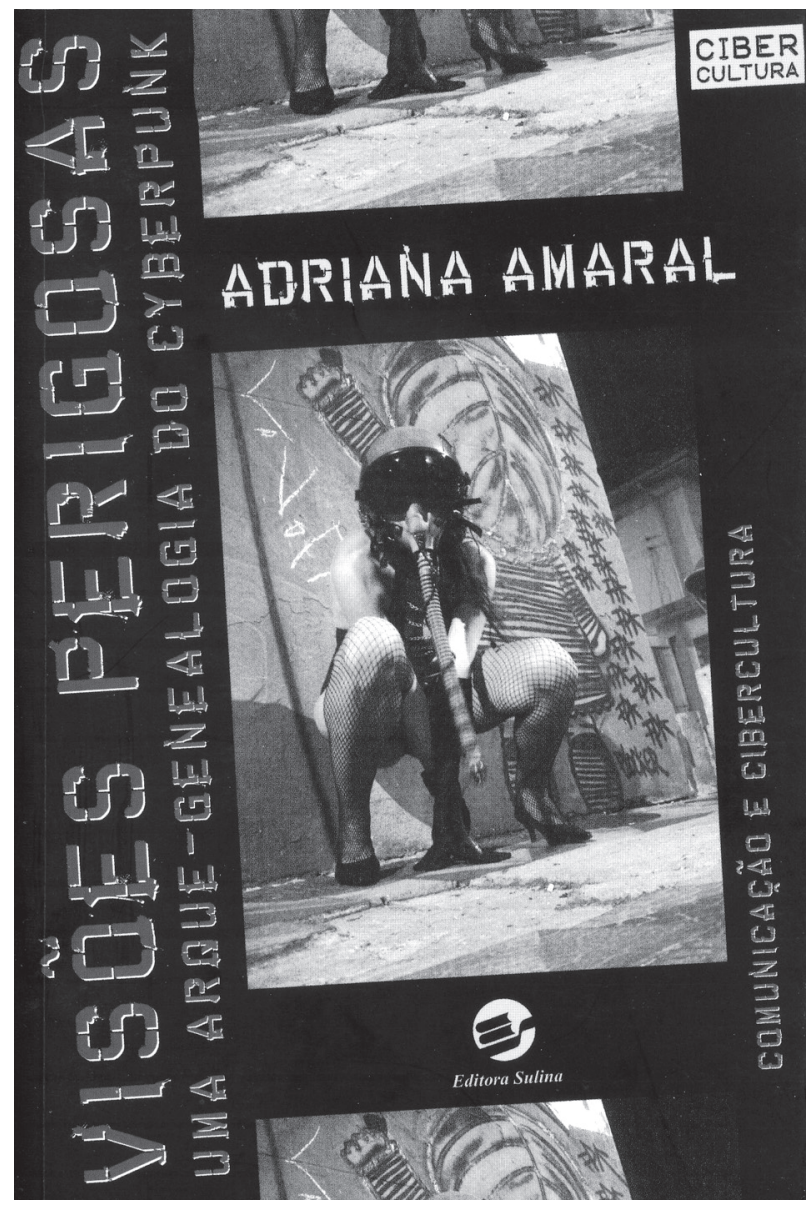

ADRIANA, Amaral. Visões Perigosas: uma arque-genealogia do cyberpunk. Porto Alegre: Editora Sulina, 2006, $239 \mathrm{p}$.

\section{Roberto Tietzmann PUCRS}

V isões Perigosas é a versão em livro da tese de doutorado defendida pela autora em 2005 no PPGCOM - FAMECOS/PUCRS e uma minuciosa exploração de diversas instâncias do cyberpunk. Desta encruzilhada entre o humano, sua negação e sua expansão através da tecnologia, da distopia e da paranóia nascem as visões perigosas de Adriana Amaral, um olhar que explica o presente através do passado e de seu imaginário de futuro.O cyberpunk é cartografado pela autora em quatro instâncias: literária (como subgênero da ficção científica), tecnológicacultural (como estética da cibercultura), social (enquanto subcultura) e cinematográfica (sintetizando horror e ficção científica). Nesta jornada, Amaral separa o livro em duas grandes partes: a primeira delas se dedica a investigar as raízes do cyberpunk antes mesmo do termo existir com o significado contemporâneo e a segunda (e mais extensa) investiga as instâncias que dialogam com a cultura ocidental do pósguerra, matriz de nossa cultura contemporânea.

$\mathrm{Na}$ abertura da primeira seção, Amaral se debruça sobre a imanência do cyberpunk sobre a cultura contemporânea. As raízes desta subcultura na ficção científica e na ciência de fato, desdobrando implicações sociais e estéticas a partir delas. O sujeito e o espaço público se encontram tecnologizados, afirma Amaral, o que abre espaço para que toda a leitura e imaginação do presente e do futuro seja pautada não mais na sua humanidade, mas na sua transcendência mesclada com a máquina.

Por um lado, temos a cibernética conceituada por Norbert Wiener, ou seja, a idéia de que é possível criar um sistema estável e auto-regulável baseado em uma máquina autônoma, e não em um organismo vivo. Tal conceito migrou para os produtos culturais de uma forma bastante livre, vinculando o acréscimo de ciberou cyber- a qualquer palavra com uma proximidade com um sistema tecnológico de criação e controle. Complementando tal noção teórica, a autora traz a interpretação deste conceito a partir da cultura libertária dos hackers californianos da década de 1960. Familiarizados com os valores liberais de movimentos sociais como os hippies, mas próximos das entranhas da indústria e da tecnologia de ponta, desta subcultura partiram os criadores dos primeiros computadores pessoais e boa parte das sementes da tecnologia de entretenimento digital que é amplamente difundida no início do terceiro milênio. Por último, Amaral aproxima a subcultura californiana com a ficção científica na pessoa e obra do escritor Philip K. Dick, prolífico autor de obras de ficção científica mais tarde identificadas com a temática cyberpunk.O cyberpunk enquanto literatura (e matriz para futuros filmes) se caracteriza como um subgênero dentro da ficção científica. A pesquisa busca as raizes do gênero desenhando uma abrangente cronologia que transita 
pelos principais autores, como Gernsback, Asimov e Clarke, além de discutir o ambígüo status que a sci-fi ocupa na literatura, equilibrando-se entre algo que agrada apenas a fãs e aficionados e uma área cujos produtos e conceitos são amplamente consumidos pelo grande público. A relação entre os dois estratos é dinâmica e Philip K. Dick é destacado como um exemplo de escritor que conseguiu cruzar a barreira que separa o underground do mainstream, ainda que isto tenha acontecido principalmente após a sua morte.A pesquisa então recua ainda mais na história, buscando não apenas as raízes imediatas da ficção científi$\mathrm{ca}$, mas seus ancestrais mais distantes. $\mathrm{O}$ ponto de ligação se dá através da recuperação das origens góticas e românticas da fiç̧ão científica e sua íntima relação com o fascínio e o medo provocado pelos avanços tecnológicos que geraram a revolução industrial do final do século XVIII em diante. Um romance na fronteira entre o gótico e o nascimento da ficção científica, afirma a autora, é Frankenstein (publicado por Mary Shelley em 1818). Nele convergem a esperança depositada no corpo refeito pela ciência e a visão sombria de suas conseqüências: um ser que não mais tem o controle de si mesmo dado pelo equilíbrio humano entre o livre arbítrio e a moral; um ser que tem algum parentesco com o humano, mas também o supera e oferece de volta um reflexo distorcido. Abandonar o corpo ou perdê-lo era o horror do romântico e uma das utopias do cyberpunk. O corpo para o cyberpunk pode bem ser um estorvo, com suas limitações e fragilidades.Na segunda parte o texto se dedica a mapear a íntima relação do cyberpunk como uma estética pop da cybercultura. Uma estética que consegue transpor os conceitos potencialmente underground em obras de diálogo com o grande público e que, no processo, abre mão de parte de sua identidade. Abrindo a segunda parte, o texto se dedica à obra e à biografia de Philip K. Dick, definido como autor seminal do subgênero cyberpunk. O autor pertence ao que foi chamada a New Wave of Science Fiction americana, movimento responsável por renovar e expandir os temas para além da utopia da conquista espacial, do otimismo tecnológico e das invasões interplanetárias. É de uma coletânea de contos New Wave lançada em 1967 que o livro da autora empresta seu título: Visões Perigosas. Dick teve uma rápida passagem pela universidade de Berkeley no final dos anos 40, dedicando-se a partir de 1951 à profissão de escritor em tempo integral. Os temas recorrentes em suas obras giram em torno de homens ordinários em profissões modestas, envolvidos em uma trama além de seu controle e sem a visão de uma redenção ou justiça final. Em Dick, a justiça, o poder, o Estado e as grandes corporações são forças de opressão do cidadão colocado sob investigação permanente.Complementando o tema da paranóia há o borramento de limites entre o que seria o "real" (dentro da história) e seu simulacro. Pistas, memórias, acontecimentos, a aparência física, o corpo e mesmo a consciência podem ser tanto verdadeiras quanto implantadas, simuladas e falsificadas em nome de uma conspiração maior sem que o protagonista perceba ou consiga libertar-se dela. Nos últimos anos da carreira, Dick direciona sua temática tech-noir progressivamente para uma espécie de êxtase místico-psicodélico, vindo a falecer antes da estréia do filme que popularizaria seu nome para as grandes audiências: Blade Runner (1982).

Como apontam os estudos culturais, cada subcultura verte seus conceitos em uma forma de produção e consumo cultural expressa em moda, música e comportamento. Um cyberpunk é, afinal de contas, mais que um punk que usa computadores e outros dispositivos eletrônicos. Segundo Amaral, as subculturas do punk e do cyberpunk dialogam através da atitude, apresentada através dos impulsos de desconstrução, de desprezo pela integridade do corpo e sua ampla modificação e do sentimento de anarquia e paranóia. O cyber do cyberpunk representa em seu princípio a síntese entre o celebrado lema "faça-você-mesmo" dos punks com a subcultura hacker surgida no pós-guerra nos centros de pesquisa de tecnologia na costa leste dos EUA somada à contracultura da costa oeste. Contudo, permanece em diálogo constante com as subculturas que a antecederam e que lhe são contemporâneas, em uma mescla de traços fortemente fragmentados e pós-modernos. Ao abordar o cinema, a autora faz uma curiosa pergunta: teríamos "cyberpunk no cinema ou um cinema cyberpunk"? A questão não é apenas um jogo de palavras, uma vez que revela algo fundamental para a transposição dos temas formulados por autores como Philip K. Dick para as telas: quem está no controle da adaptação? Os temas são incorporados como uma moda passageira ou se tornam traços definidores de filmes, a ponto de poderem ser agrupados em um movimento coeso? Apesar de várias histórias de Dick terem sido adaptadas como filmes de longa metragem de grande sucesso, a conclusão que a autora chega é que não há um corpus cyberpunk no cinema coeso e numeroso o suficiente para caracterizá-lo como um subgênero claramente delimitado e distinto da ficção científica como um todo. Os temas de tecnologia, controle, paranóia e transcendência do corpo são usados em diversos filmes, mas em geral apresentam-se de forma diluída em seu desenvolvimento e resolução. Diversas obras de Philip K. Dick no cinema oferecem a seus espectadores, por exemplo, finais felizes e libertadores a seus protagonistas.Ao concluir a arqueologia do cyberpunk e a exploração das suas diversas instâncias, a autora encerra sua obra apontando a disseminação de tais idéias na sociedade e cultura contemporâneas, envolvidas em um contexto de progressivo controle e vigilância mediado e proporcionado pela tecnologia e pela digitalidade cada vez mais onipresente. As idéias do cyberpunk, portanto, servem ao mesmo tempo de reflexo do contemporâneo e sua extrapolação para um futuro possível; um retrato e também uma projeção; um delinear e um devir. mfamecos 